\title{
Intra Urban Air Temperature Distributions in Historic Urban Center
}

\author{
Elmira Jamei and Dilshan Remaz Ossen
}

\author{
Department of Architecture, Faculty of Built Environment, \\ University Technology Malaysia, UTM Skudai, 81310 Johor, Malaysia
}

Received 2012-06-23, Revised 2012-07-25; Accepted 2012-08-17

\begin{abstract}
The study investigates the urban heat island effect in Malaysian historic town Malacca through seven mobile traverses, as carried out on 10 December 2011. It aims to identify the intra-urban air temperature differences between heritage core zone, new development area and outskirts of the city. Air temperature variations were also analyzed across three different zones; namely the outskirts, the heritage site and the city center district. Heat index values were then calculated based on air temperature and relative humidity to gauge the level of outdoor thermal comfort within the study area. Based on the indications, one may conclude that the heritage place's core zone is currently threatened by escalating temperatures and that its current temperature range falls within the "caution" and "extreme caution" categories. Furthermore, no significant difference was observed between the peak temperatures of the old city quarters and newer areas; despite the disparities in their urban forms. Therefore, it is hoped that the study, with its implications, will be able to influence future environmental consideration in heritage city of Melaka.
\end{abstract}

Keywords: Heritage Area, Intra-urban Temperature, Heat Index, Tropical Climate, Mobile Traverse

\section{INTRODUCTION}

Urbanization has been associated with numerous environmental issues in developing countries; moreso those with tropical climates. In fact, since a comfortable climate plays an important role in attracting people to urban environments, several studies have been published concerning the effects of urbanization on indoor and outdoor thermal comfort, energy consumption and urban climate; the latter of which is characterised by a higher air temperature in urban centers as compared to the surrounding rural areas. This variation in air temperature is also applicable inter-city or between different locations within the same city.

Such intra-urban temperature differences have already been emphasized in past research (Eliasson, 1992; Unger, 2004). There are records of the the urban heat island effect in dense urban centers reaching as high as up to $12 \mathrm{~K}$ (Johnson et al., 1991). In one case, the measurements procured at 30 sites in Goteborg, Sweden presented an intra-urban temperature discrepancy of $9^{\circ} \mathrm{C}$ (Svensson et al.,
2002). On the other hand, similar fieldwork in three large housing estates from Hong Kong produced a mere $1^{\circ} \mathrm{C}$ temperature difference between the estates (Giridharan et al., 2004).

As a tropical developing country, Malaysia, too has gained increasing attention in the field of urban climate. Recent ventures have affirmed the existence of heat islands in Kuala Lumpur (Sani, 1973) and Johor Bahru (Kubota and Ossen, 2009), whereas a series of observations in Kuala Lumpur (Sani, 1987) found a $4-4.5^{\circ} \mathrm{C}$ temperature gap between urban and rural areas. Meanwhile, studies by Kubota and Ossen (2009) in Johor Bahru point to a nocturnal urban-rural temperature difference of only $2^{\circ} \mathrm{C}$ on rainy days that peaks at $4^{\circ} \mathrm{C}$ in sunnier weather.

Land use and zoning have been cited as two key determiners in intra-urban temperature differences (Upmanis and Chen, 1999). This is demonstrated by a twelve-year study in Kuala Lumpur, in which commercial districts had temperatures several degrees higher compared to their bordering outskirts (Sani, 1973). Another study by Johansson (2006) in Fez,

Corresponding Author: Elmira Jamei, Department of Architecture, Faculty of Built Environment, University Technology Malaysia, UTM Skudai, 81310 Johor, Malaysia 
Morocco inferred that the old town area, with its deep street canyon, had better outdoor comfort compared to those provided by the shallow street canyons in the newer development areas.

However, few studies were actually conducted to understand the heat island effect in urban heritage areas as compared to new development districts; as this study now attempts in Malacca.

Since Malacca became a world heritage site in 2008, its flourishing local tourism industry and the related activities have demanded many immense changes of the city. Alterations have been imposed upon the city's structure, living conditions and most importantly, to the urban environment. This in turn affected the heritage's environment; resulting in more anthropogenic heat, higher energy consumption and a reliance on air conditioners to provide the indoor thermal comfort within the heritage core zone.

To summarise, the unavoidable impacts of urbanization and population growth within Malacca encompass a change to the urban environment of heritage core zone, which affects the citizens' thermal comfort. It is with the intention of addressing these important issues that the study investigates the intraurban temperature differences between the heritage core zone, new development area and the outskirts of the city.

\section{MATERIALS AND METHODS}

\subsection{Description of Study Area}

The city of Malacca is located on the west coast of the Malay Peninsula. With the coordinates $2.29^{\circ} \mathrm{C} \mathrm{N} 102.30^{\circ} \mathrm{E}$, it lies approximately 147 kilometers from Kuala Lumpur. Facing the Straits of Malacca on the west, the town is also enclosed on the east and north by mountains and tropical rainforests respectively. Its population of 788,706 experience a hot and humid climate throughout the year; in which daily temperatures average $21-32^{\circ} \mathrm{C}\left(70-90^{\circ} \mathrm{F}\right)$, humidity is usually at $90 \%$ and monsoon season occurs during September and December.

The town is divided into two parts with distinct urban forms. The heritage core zone (Fig. 1) refers to the old city quarters while the city center, (Fig. 2) represents the contemporary city of Malacca.

Malacca's old division is compact in form. The street networks in the heritage core zone are laid in a grid pattern and the ratio of building height to street width is about 1:1 in most passages. Hence, these street spaces are well shaded by the two- or three-storey shop-houses lining both sides of the narrow streets. Within the heritage core area, the ground is paved with concrete, tile and asphalt. Little exists of natural surfaces; as buildings, too, are composed of clay tile roofs and pale, laterite walls. Recent years have only furthered this state along. Major developments were concentrated specifically around the heritage core zone to expand upon the city center. In a vast contrast to the older quarters, the new city center district has been designed for vehicles and has wide and pavemented streets. Other major features include buildings of varied heights and more diversity in their construction materials than the homogeneities of the shop houses in the heritage core zone.

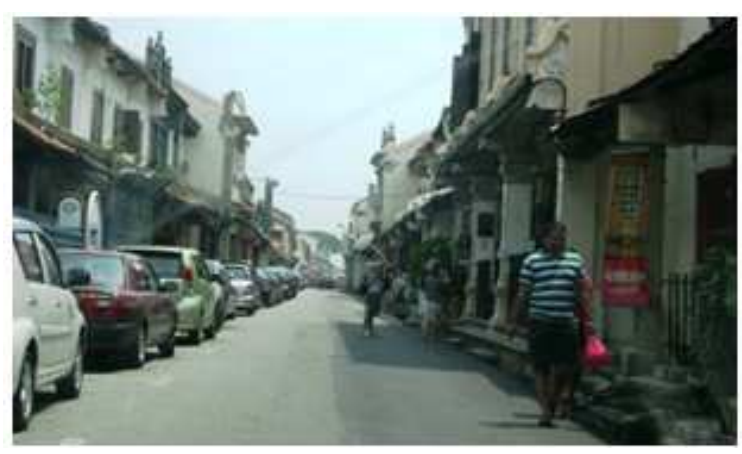

Fig. 1. Homogeneous shop houses in heritage core zone

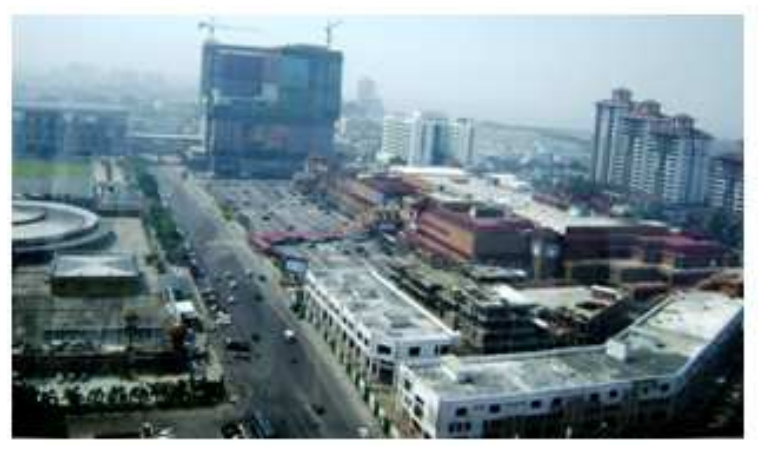

Fig. 2. New developments in city center district

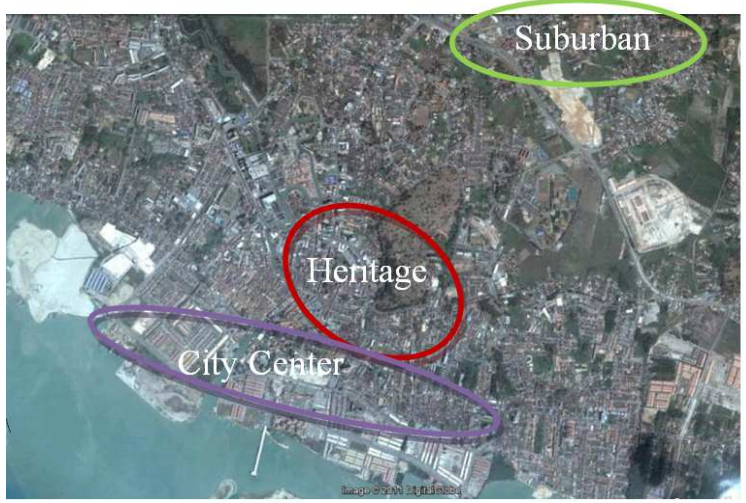

Fig. 3. Green, red and purple delineate the three selected zones of the suburbs, the heritage core zone and the city center district respectively 


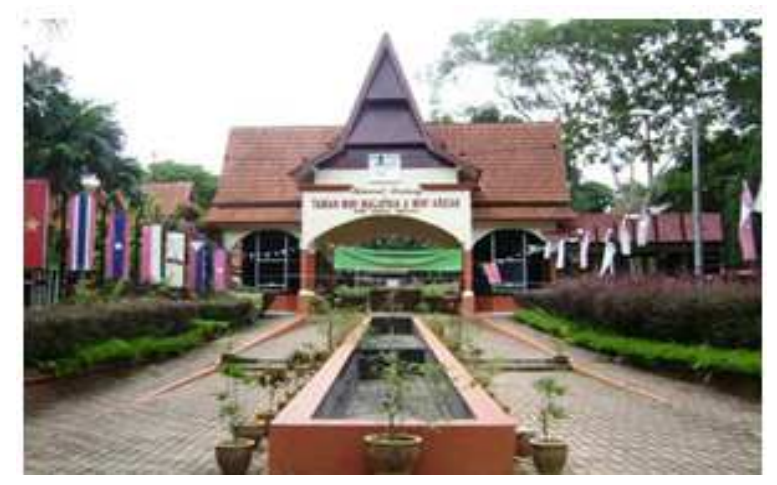

Fig. 4. The first fixed weather station, Taman Mini Malaysia

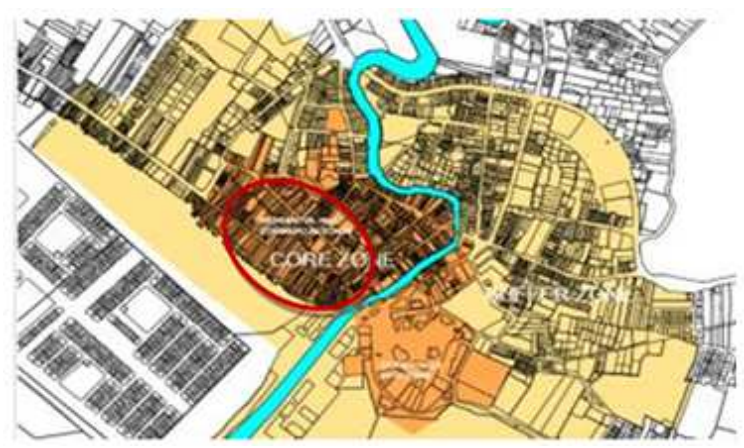

Fig. 5. The location of the second fixed weather station, Puri Hotel

In this research, the study area has been confined to three main zones: the heritage core zone, the city center and a suburban area situated immediately at the perimeter of the urban center (Fig. 3).

\subsection{Fixed Weather Station}

Two locations were selected to installed the fixed stations one at cultural park located $20 \mathrm{~km}$ from city center in a suburban area and surrounded by green vegetation (Fig. 4). The second station was installed at middle of the historical part of the town within $2-3$ storey high hotel.

The second point of measurement is encircled by two-or three-storey shop houses and the streets running through it are oriented towards the northwest and southeast (Fig. 5).

In the experiment, readings for air temperature and humidity were recorded at the weather stations; at a height of 2 meters off the ground. Wind speed was also measured with a manual data logger at the same height at the end of every traverse. The results were then collected from both fixed and mobile traverses within a period of $24 \mathrm{~h}$, so as to take the differences of daytime and nightime into account. Weather conditions prior to and during the data collection were clear and free of rain.

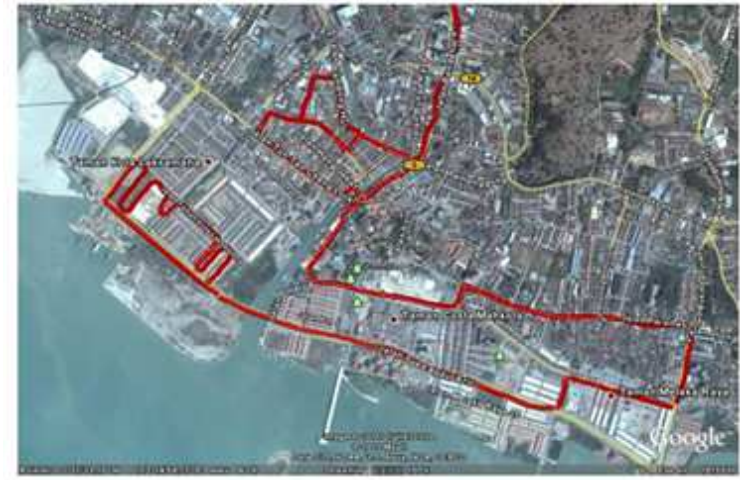

Fig. 6. The selected path for conducting the mobile traverses

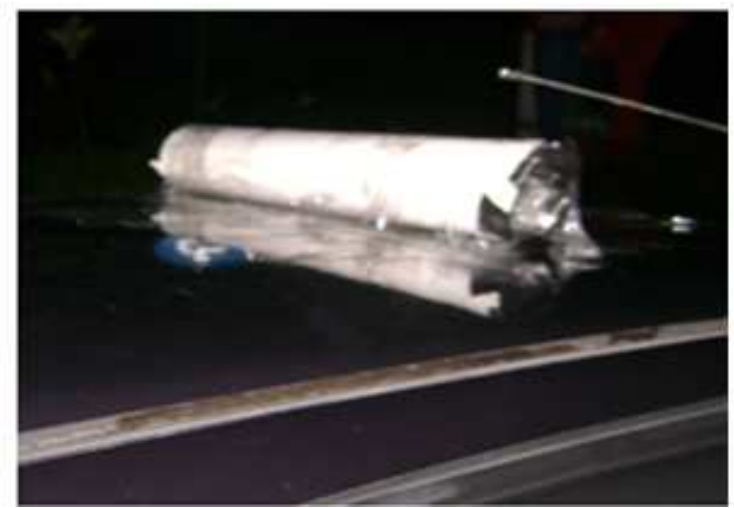

Fig. 7. Data logger attached on the roof of the car

Table 1. Mobile traverses

\begin{tabular}{lc}
\hline Traverse no. & Duration of traverse \\
\hline Traverse1 & $4.30-5.25 \mathrm{am}$ \\
Traverse2 & $8.00-9.00 \mathrm{am}$ \\
Traverse3 & $11.30-12.40 \mathrm{am}$ \\
Traverse4 & $15.06-16.14 \mathrm{pm}$ \\
Traverse5 & $19.20-20.22 \mathrm{pm}$ \\
Traverse6 & $23.40-00: 34 \mathrm{pm}$ \\
Traverse7 & $3.00-3.58 \mathrm{pm}$ \\
\hline
\end{tabular}

\subsection{Weather Data Collection Using Mobile Traverse}

The comprehensive mobile traverses were undertaken on 10 October 2011 to determine the intra urban air temperature differences in the city of Malacca compared to suburban air temperature.

The first mobile traverse commenced at 4:30 am and the last was completed at 3:30 am the following day. Figure 6 shows the travelled route for the mobile survey.

The data logger was installed in well insulated PVC tube and was fixed on a vehicle roof (Fig. 7). The data logger automatically recorded ambient air temperature and humidity in 2 min interval. 
All in all, a total of seven trips were carried out in the clear and cloudless weather and their durations are as stated in Table 1.

\subsection{Heat Index}

Heat Index (HI) is the most widely-cited outdoor weather stress indicator that defines the human response to the heat (Parsons and Griffin, 1993). It was developed by the National Weather Service (NWS) in1978,based on Steadman $(1979 ; 1984)$ apparent temperature concept and is vital to the understanding of heat and humidity's impact on the human body. According to the National Weather Service, when heat gain exceeds levels the body can remove by itself, body temperature begins to rise and heat-related illnesses and disorders may develop. For this reason, $\mathrm{HI}$ is used to alert the public about the potential health hazards of hot weather, but it has also been applied in the field of thermal comfort research; as in the case of Emmanuel (1997), who employed it to analyze the effects of high-density development on human thermal comfort. Given the sufficient quality literature available where heat index has been used as an comfort index responsive to stressful environments, this study, too, follows suit while evaluating the level of thermal comfort.

$\mathrm{HI}$ is derived from the following equation (Eq. 1) in degrees Fahrenheit. Estimated range for error is $\pm 1.3^{\circ} \mathrm{F}$; the reason being a multivariate fit (of temperatures of at least $80^{\circ} \mathrm{F}$ and relative humidity at a minimum of $40 \%$ ) to a model of the human body. HI values are converted to centigrade for analysis:

$$
\begin{aligned}
& \mathrm{HI}=\mathrm{C}_{1}+\mathrm{C}_{2} \mathrm{~T}+\mathrm{C}_{3} \mathrm{R}+\mathrm{C}_{4} \mathrm{TR} \\
& +\mathrm{C}_{5} \mathrm{~T}^{2}+\mathrm{C}_{6} \mathrm{R}^{2}+\mathrm{C}_{7} \mathrm{~T}^{2} \mathrm{R}+\mathrm{C}_{8} \mathrm{~T}^{2} \mathrm{C}_{9} \mathrm{~T}^{2} \mathrm{R}^{2}
\end{aligned}
$$

Where:

$\mathrm{HI}=$ Heat index (in degrees Fahrenheit)

$\mathrm{T}=$ Ambient dry-bulb temperature (in degrees Fahrenheit)

$\mathrm{R}=$ Relative humidity (in percent)

The equation is valid only if $\mathrm{T}$ is $\left(70^{\circ} \mathrm{F}\right)$ and above.

Table 2 illustrates the range of $\mathrm{HI}$ values. As can be observed, a heat index below $27^{\circ} \mathrm{C}$ represents the ideal. Once the heat index reaches the values marked in yellow, a further increase in temperatur-and the corresponding darkening of the temperature range's indicative color-brings the heat index closer to the "Extreme Caution" zone. Serious cases at $32^{\circ} \mathrm{C}$ and above necessitates decisive action to preserve the environment of the affected area.
Table 2. Heat Index

\begin{tabular}{lll}
\hline Heat index $\left({ }^{\circ} \mathrm{C}\right)$ & & Possible action \\
\hline Below 27 & Neutral & Preserve enhance \\
$27-32$ & Caution & Action desirable \\
$32-41$ & Ex-cuation & Action necessary \\
$41-54$ & Danger & Action necessary \\
Over 54 & Ex-danger & Action necessary \\
\hline
\end{tabular}

\section{RESULTS AND DISCUSSION}

\subsection{Temperature Variation Across The Zones}

In this study, the air temperature variation was measured across three different zones, (outskirt, heritage area and city center), to identify the effect of land use zoning on the air temperature of study area.

Figure 8 shows that urban areas are generally warmer than the surrounding rural areas.

It also demonstrates how the air temperature fluctuates across different zones of the study area in every single traverse, for which a constant trend is exhibited. Overall, the air temperature is at its lowest in the suburbs $(25.60,25.76,32.74,33.04,27.14,26$ and $24.64^{\circ} \mathrm{C}$ ) and increases gradually when entering the heritage core zone; thus charting its highest values in the city center $(25.86,29.74,37.39,37.48,30.44$, 28.99 and $26.69^{\circ} \mathrm{C}$ ).

Figure 9 shows that the town experiences its warmest hours between 11:30am-16:15pm (as recorded by traverse 3 and traverse 4 ). It is also reveals that, despite the differences in urban character between the heritage core zone and city center, the range of air temperatures are considerably similar.However, the air temperature in heritage core zone does exceed that of the city center at certain times of the day (traverse 4; 15: 06-16:14).

Based on the values featured in the previous two tables, the intra-urban air temperature differences were calculated and depicted in Fig. 10. The highest recorded was $5.09^{\circ} \mathrm{C}$ between the city center and outskirts at 12:20 noon. Incidentally, the largest gap between the temperatures at the heritage site and the outskirts $\left(4.3^{\circ} \mathrm{C}\right)$ was obtained a mere $8 \mathrm{~min}$ later; as the blue columns denoting this discrepancy in Fig. 10 indicate. Generally, the range of air temperatures in the core zone and city center display remarkable likeness, the highest difference between them was recorded at 4:12 pm by $2.14^{\circ} \mathrm{C}$. 


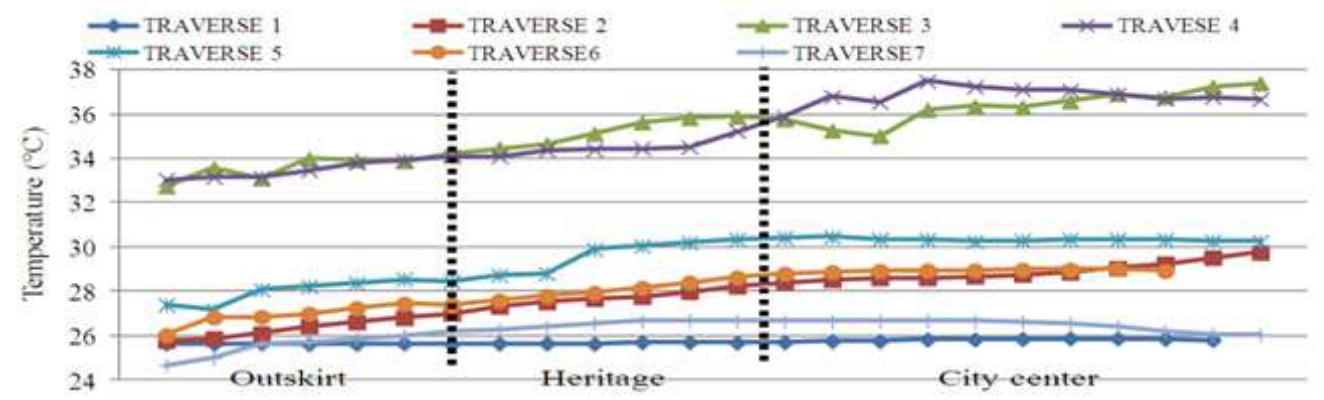

Fig. 8. Temperature variation across three zones

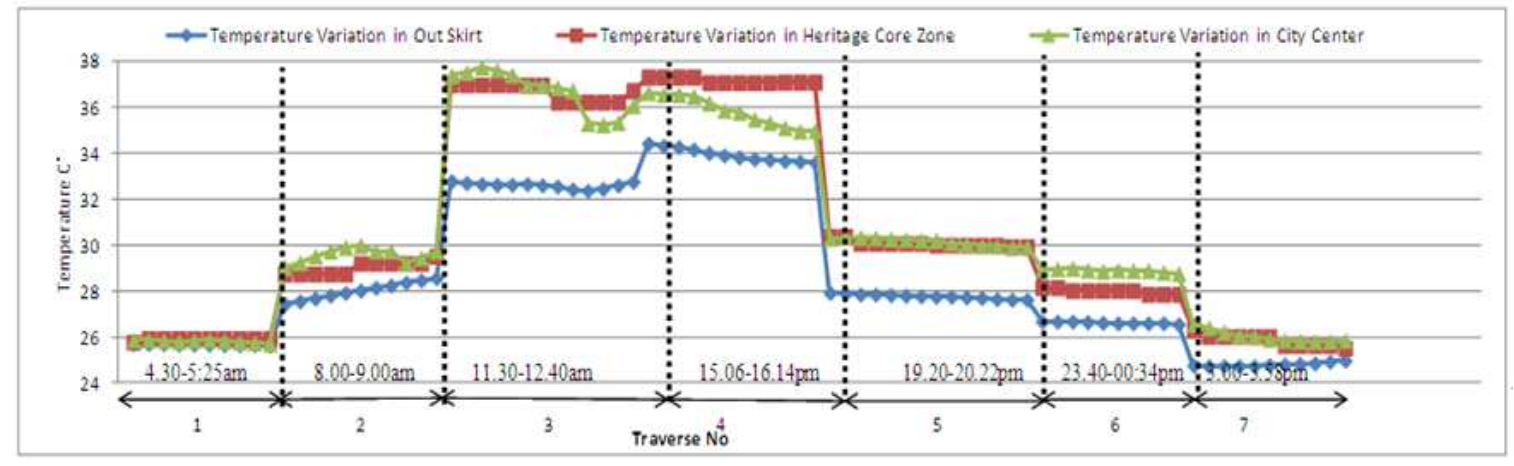

Fig. 9. Temperature variations in every single traverse

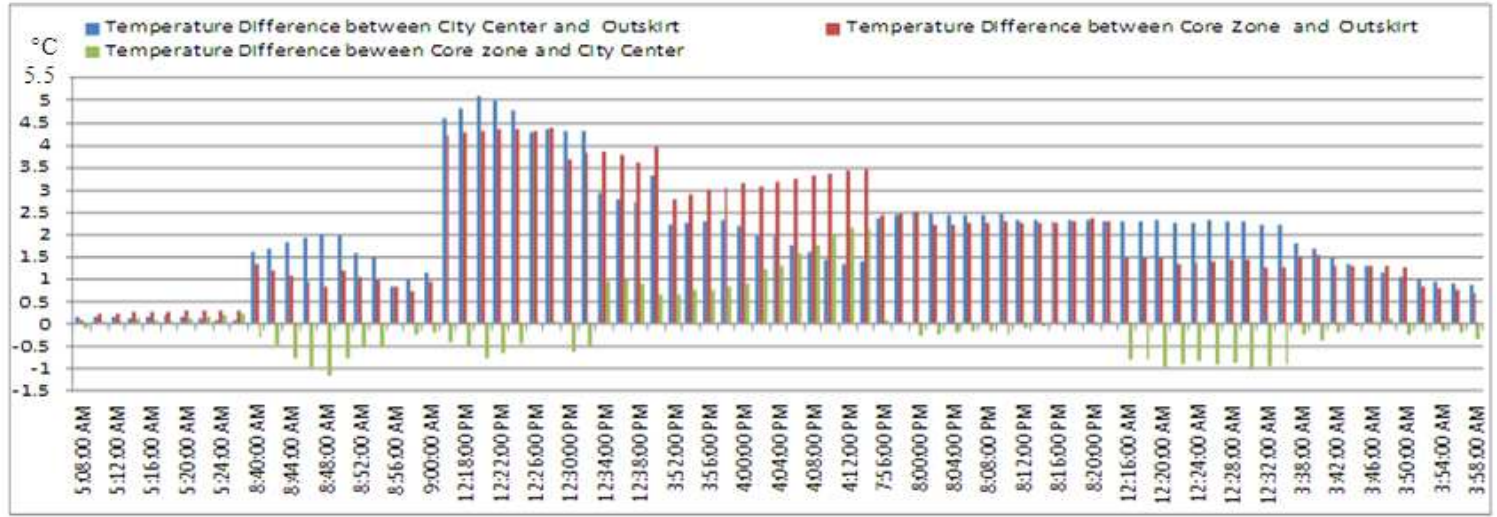

Fig. 10. Temperature differences between study areas

\subsection{Assessment of Thermal Comfort}

Thermal comfort was also assessed by calculating the heat index in degrees centigrade.

Figure 11 indicates the ranges of temperature and heat index fluctuation within the study period. Blue signifies air temperature variation whilst red stands for the heat index. It also gives the exact times when the temperature enters the "caution", "extreme caution", "danger" and "extreme danger" zones; as this would entail action to preserve the urban environment of the heritage core zone.

Based on Fig. 12, the peak heat index is recorded between 3 to $4 \mathrm{pm}$. Therefore, significant considerations should be made concerning future human activity, particularly during hot afternoons. 


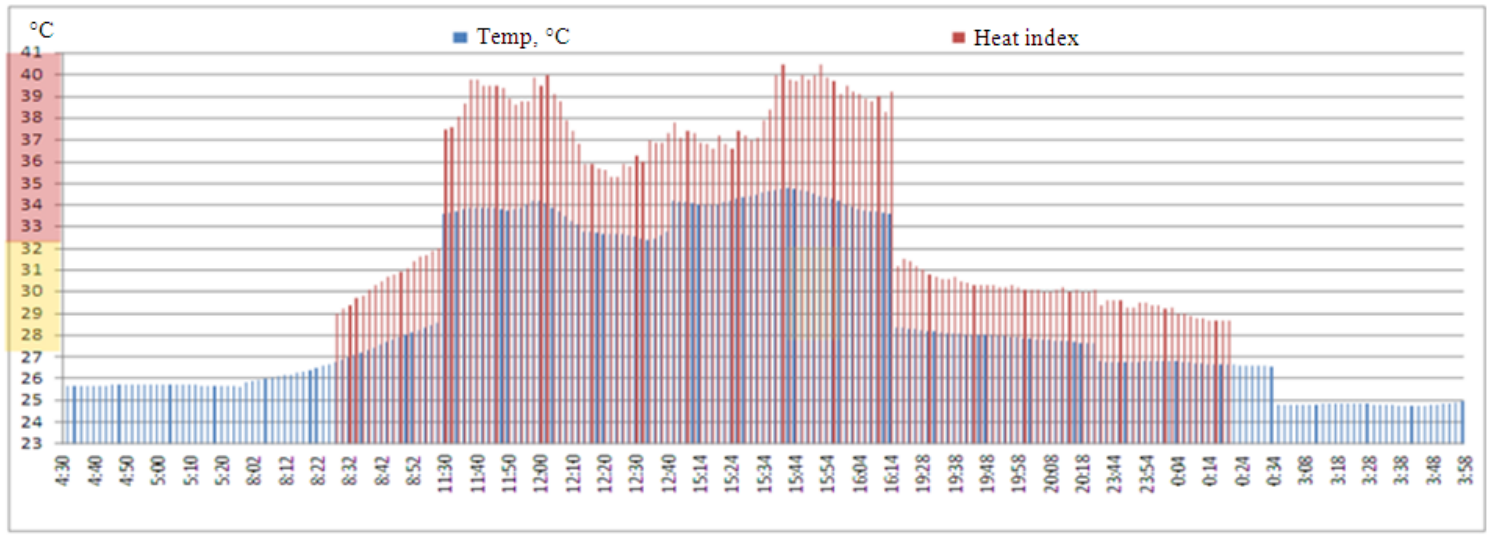

Fig. 11. Variation of Temperature and related Heat index against time

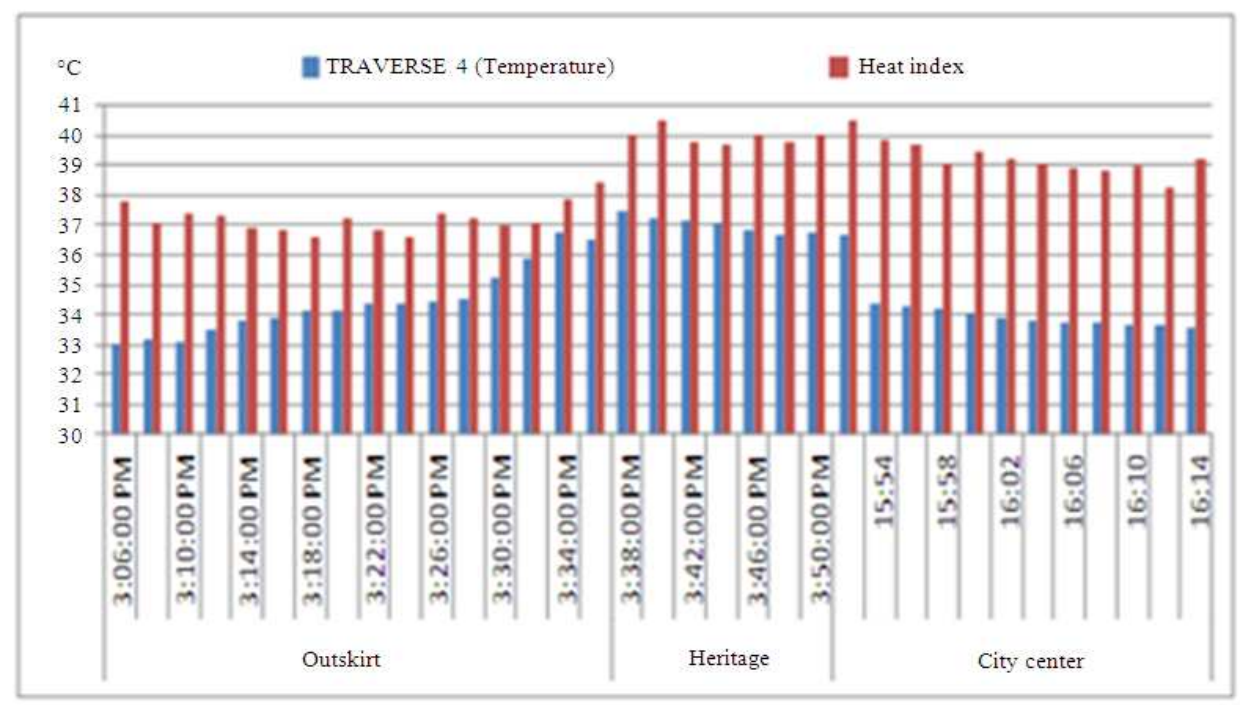

Fig. 12. Temperature and heat index range for traverse 4

Table 3. Variation of wind speed in the core zone and along the sea

\begin{tabular}{lcc}
\hline Time & $\begin{array}{l}\text { Wind speed } \\
\text { beside the sea }(\mathrm{m} / \mathrm{sec})\end{array}$ & $\begin{array}{l}\text { Wind speed in } \\
\text { heritage area }(\mathrm{m} / \mathrm{sec})\end{array}$ \\
\hline 9.00 & 0.7 & 0.60 \\
13.00 & 1.9 & 1.80 \\
$14: 30$ & 0.9 & 1.20 \\
20.30 & 0.0 & 0.05 \\
\hline
\end{tabular}

Taking traverse 4 as the example (this being the one where the peak heat index was recorded), it can be seen that the heat index is lowest in the suburbs. At the heritage core zone and city center, the heat index goes as high as $40.5^{\circ} \mathrm{C}$ and averages roughly 39.9 and $39.2^{\circ} \mathrm{C}$ respectively. Therefore, it can be safely surmised that the historical part of Malacca faces the threat of high temperatures.

\subsection{Wind Effect}

Table 3 records wind speed in two different locations within the study area. Although the area is close to the sea the results show that the effect of the wind is insignificant.

\section{CONCLUSION}

This study was an effort to demonstrate the intraurban air temperature difference in the historic city of 
Malacca and highlight its needs of environmental considerations; which will lead to numerous consequences on the local tourism industry, heritage conservation and economy growth.

This difference in air temperature was derived from the values registered at the heritage core zone, city center and suburban area. The results unearthed differences in the heat index values, even between the city center and core zone, that have never been reported before.

Despite the different urban forms possessed by the heritage core zone and newly developed city center, their air temperature differences were virtually negligible; proving that the more historical parts of the town are not spared from the danger of rising temperatures as well.

The intra-urban air temperature differences in Malacca also confirmed the existence of urban heat islands in this town; the intensities of which differ depending on the selected area.

Aside from that, the considerable values charted by the heat index in the heritage core zone, especially during the afternoons, make it a rather uncomfortable visit for tourists. A heavy dependence of air conditioners and the subsequent energy consumption is almost inevitable.

Finally, the heat index can be employed to numerate the level of outdoor thermal comfort in case studies, particularly in tropical countries with a high level of humidity and outdoor temperature. Nevertheless, the research would be more comprehensive if the heat index values did not rely on the temperature and humidity alone, but included the responses from a questionnaire and interviews with subjects as well.

\section{ACKNOWLEDGMENT}

Special thanks go to Associate Professor Dr. Tetsu Kubota and Ms Dorris from Hiroshima University, Japan for much assistance in the process of data-gathering.

\section{REFERENCES}

Eliasson, I., 1992. Infrared thermography and urban temperature patterns. Int. J. Remote Sens., 13: 869879. DOI: $10.1080 / 01431169208904160$

Emmanuel, M.D.P.R., 1997. Summertime heat island effects of urban design parameters. University of Michigan.
Giridharan, R., S. Ganesan and S.S.Y. Lau, 2004. Daytime urban heat island effect in high-rise and high-density residential developments in Hong Kong. Energy Build., 36: 525-534. DOI: 10.1016/j.enbuild.2003.12.016

Johansson, E., 2006. Influence of urban geometry on outdoor thermal comfort in a hot dry climate: A study in Fez, Morocco. Build. Environ. 41: 13261338. DOI: 10.1016/j.buildenv.2005.05.022

Johnson, G.T., T.R. Oke, T.J. Lyons, D.G. Steyn, I.D. Watson et al., 1991. Simulation of surface urban heat islands under 'IDEAL' conditions at night part 1: Theory and tests against field data. BoundaryLayer Meteorol., 56: 275-294. DOI: 10.1007/BF00120424

Kubota, T. and D.R. Ossen, 2009. Spatial characteristics of urban heat islands in Johor Bahru City, Malaysia. Proceedings of the 3rd South East Asian Technical Universities Consortium (SEATUC' 09), Johor Bahru, Malaysia, pp: 39-44.

Parsons, K.C. and M.J. Griffin, 1993. Ride quality and thermal comfort for railway passengers. Med. Eng., 7: 75-75.

Sani, S., 1973. The urban heat island: Its concept and application to Kuala Lumpur. Sains Malaysiana. 2: 53-64.

Sani, S., 1987. Urbanization and the atmospheric environment in the low tropics: Experiences from the Kelang Valley Region, Malaysia. Universiti Kebangsaan Malaysia, Bangi.

Steadman, R.G., 1979. The assessment of sultriness. Part II: Effects of wind, extra radiation and barometric pressure on apparent temperature. J. Applied Meteorol., 18: 874-885.

Steadman, R.G., 1984. A universal scale of apparent temperature. J. Applied Meteorol., 23: 1674-1687.

Svensson, M.K., I. Eliasson and B. Holmer, 2002. A GIS based empirical model to simulate air temperature variations in the Goteborg urban area during the night. Climate Res., 22: 215-226. DOI: $10.3354 / \mathrm{cr} 022215$

Unger, J., 2004. Intra-urban relationship between surface geometry and urban heat island: Review and new approach. Clim. Res., 27: 253-264.

Upmanis, H. and D. Chen, 1999. Influence of geographical factors and meteorological variables on nocturnal urban-park temperature differences- a case study of summer 1995 in Goteborg, Sweden. Clim. Res., 13: 125-139. 